\section{Saneamiento ambiental urbano, una propuesta de integración socioespacial}

\author{
Miguel Ángel Vitale \\ María Alicia Follonier \\ Docentes investigadores \\ de la Facultad de Arquitectura, \\ Diseño y Urbanismo. \\ Universidad Nacional del Litoral.
}

Universidad y salud /

Intervenciones
Resumen

El Proyecto de Extensión llevado adelante por un grupo de docentes investigadores de la Universidad Nacional del Litoral (UNL) se propuso ofrecer alternativas de saneamiento ambiental al aglomerado urbano Reconquista/ Avellaneda, situado a $325 \mathrm{~km}$ al norte de la ciudad de Santa Fe. A partir del reconocimiento de contextos de incidencia de actuaciones (globales, regionales y locales), la propuesta se ocupó de las condiciones de salubridad de la población a causa de la degradación biológica por contaminación del arroyo El Rey, lo que afecta a 130000 personas.

El área analítica propositiva se incluye en uno de los 21 humedales Ramsar de reserva nacional de Argentina. El proyecto, su difusión y metodología participativa concientizaron a los ciudadanos sobre este vital recurso y, a partir del debate con las instituciones de la sociedad civil y el gobierno local, identificó alternativas viables y concretas, sostenibles e integracionistas, y llegó a una propuesta final presentada públicamente.

Palabras clave

- ambiente

- saneamiento

- sustentabilidad

- urbanidad

- espacio público

- paisajística

\section{Contexto institucional académico}

En el marco de la Secretaría de Extensión de la UNL se desarrolló el Proyecto de Extensión de Interés Social (PEIS 2012), denominado "Integración socioespacial y multiactoral urbana territorial del aglomerado Reconquista/Avellaneda", vinculado al Programa de Extensión Ambiente y Sociedad, con sede académica en la Facultad de Arquitectura, Diseño y Urbanismo. El proyecto está destinado a actores sociales barriales pertenecientes a ese aglomerado y de la región, como también a actores institucionales, profesionales y universitarios. Desde una perspectiva de integración de diferentes actores, disciplinas vinculantes y transferencia de conocimientos, se estructuró la propuesta mallando el sentido, intereses y objetivos del grupo de extensión y la política extensionista de la UNL:

"A partir de la vinculación con determinados grupos de la comunidad local y regional, los proyectos se proponen abordar y transferir conocimientos adquiridos tanto en docencia como en investigación. Para su ejecución se establecen temas prioritarios — de interés social— que se articulan con las líneas de acción de los Programas de Extensión. Los equipos de trabajo son interdisciplinarios y están conformados por docentes, graduados y alumnos de diferentes unidades académicas de la UNL" (Secretaría de Extensión,

Proyecto de Extensión de Interés Social).

\section{Contextualización del proyecto: la propuesta}

El contexto social que dio origen al problema a resolver se articuló en tres niveles:

- El contexto global: los procesos de mundialización y globalización resitúan las problemáticas socioespaciales de ciudad y territorio.

Así, los asentamientos urbanos se dualizan, operan e inducen sus decisiones desde la preexistencia y su condición de centralidad, simultáneamente prescinden de sus propias coordenadas geográficas y geofísicas, ingresan a un sistema de competencias sin centro, ageográfico, y virtualizan su propia densidad y rol urbano. Estos procesos que en muchos casos desdeñan las lógicas internas socioespaciales de las ciudades, marcan claramente la disyunción entre la cultura del localismo y las decisiones planetarias, observándose casos de superposiciones, contigüidades y sustituciones entre los discursos hegemónicos y los nuevos situacionismos sustentables que impactaron en la realización del proyecto.

- El contexto regional: a la situación anterior de la disyuntiva entre global y local se suma que el territorio santafesino ha sufrido históricamente la bifrontalidad. El sur económicamente potenciado, ligado a los cordones industriales y a las tierras fértiles de la pampa húmeda, manifiesta un desarrollo territorial en consonancia con estándares aceptables y equilibrados de calidad de vida urbana. En contraposición, el norte aparece como relegado en 


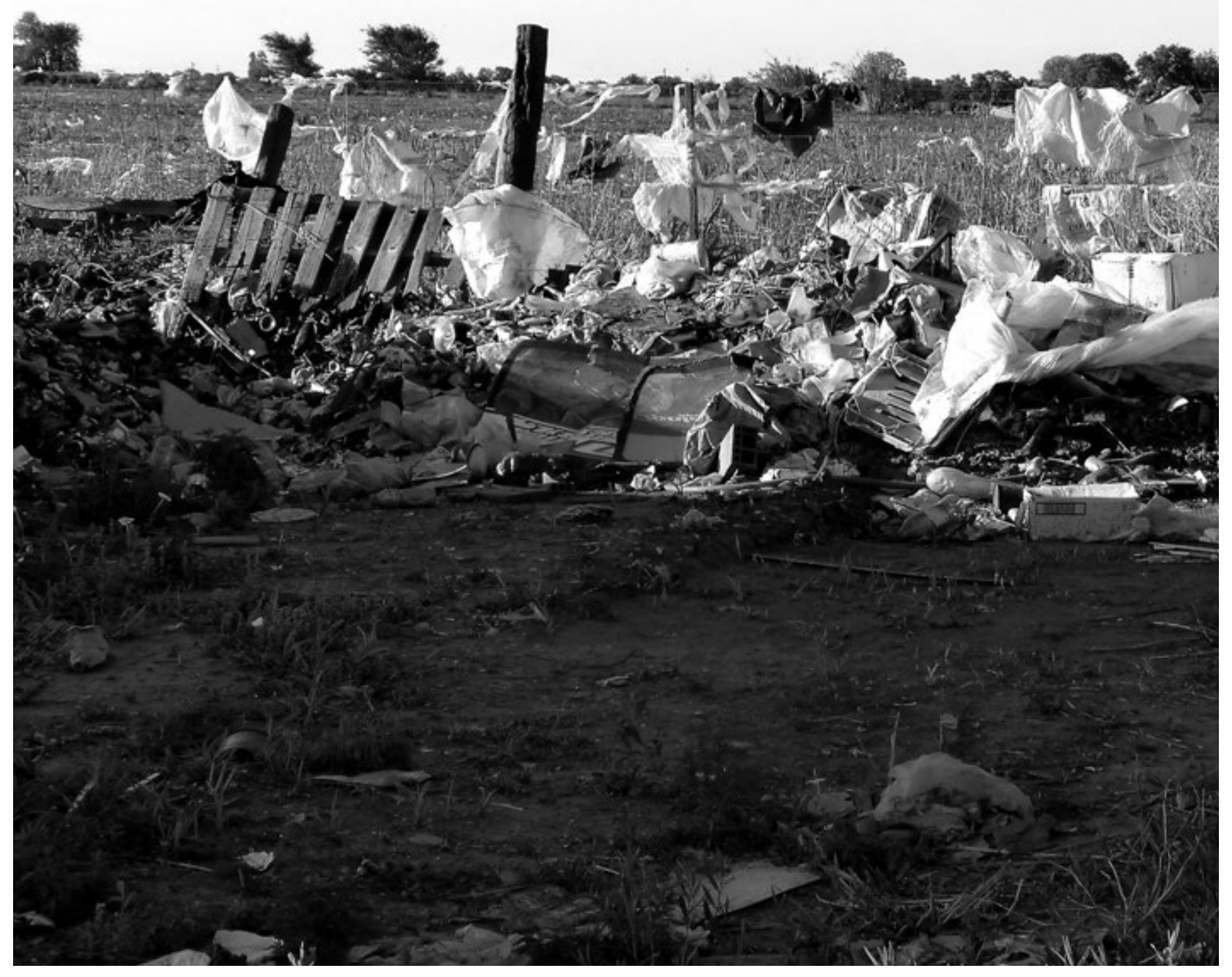


sus posibilidades de desarrollo económico social, marcadamente librado a economías focales extractivas no renovadas y sostenido en parte por decisiones políticas de subsidiación estatal, sea a emprendimientos de PyMEs o a incipientes industrias locales, para la provisión de viviendas y servicios, y con alto nivel de empleo público. Esta situación no siempre permitió que las ciudades y poblaciones sostuvieran un relato armónico entre las espacialidades urbanas, los espacios públicos, las expansiones controladas, las apropiaciones físico-simbólicas, la sustentabilidad ambiental de recursos, entre otros indicadores. En tal sentido, el proyecto se propuso como herramienta que democratice la espacialidad urbana regional y admita alternativamente superar la disonancia socioespacial, tomando el aglomerado Reconquista/ Avellaneda como foco de transferencia, contrastación y soporte físico de una proyectualidad mancomunada e integracionista. - El contexto local: este aglomerado urbano cuenta con 130000 habitantes. Tanto Reconquista como Avellaneda, si bien comparten recursos territoriales, ambientales y sociales, tienen bien marcada sus especificidades. Reconquista se conformó con una población de inmigrantes que cultivaban la tierra, lo que generó desarrollo comercial e industrial incipiente referido a industrias cárnicas. Posteriormente comenzó la formación de profesionales demandados por la especialización de las industrias y se crearon instituciones universitarias en el medio, en un ambiente urbano más cosmopolita. Avellaneda, también con población de origen de inmigrantes, es uno de los centros industriales más importantes del norte santafesino: tiene significativos establecimientos fabriles que procesan fundamentalmente materias primas agrícolas y productos base para la industria alimenticia nacional, entre cuyas producciones más destacadas está la de aceite crudo. Su población es de un nivel socioeconómico más equilibrado, lo cual propicia un ambiente urbano más homogéneo.

Tres sectores industriales localizados en el aglomerado constituyen un importante polo de desarrollo de la economía regional y, a la vez, son fuente de contaminación ambiental:

- El frigorífico, con residuos que contienen sangre, efluentes grasos, orín y estiércol.

- El aceitero, contaminante por sus efluentes líquidos, lodos producidos en su tratamiento y olores molestos.

- La curtiembre, cuyos desperdicios tienen un alto nivel de alcalinidad, sulfuro, nitrógeno, sólidos disueltos y suspendidos, aceite y grasa, con gran demanda de oxígeno bioquímico y químico, produciendo aguas servidas con un alto contenido de ácidos y sales.

El panorama productivo de la región se complementa con la actividad ganadera extensiva, que abastece primordialmente el mercado local. Desde la perspectiva de las localizaciones urbanas, se detectó que los barrios Almafuerte y Norte, que conforman el borde lindante norte de la ciudad de Reconquista sobre el arroyo El Rey y el barrio Moreno hacia la izquierda de la Ruta Nacional $\mathrm{N}^{\circ} 11$, son los más directamente afectados por la baja calidad habitacional dada la degradación ambiental de la zona a causa de los efluentes arrojados al arroyo por las industrias locales, del mismo modo son afectados el área del camping, el espacio público más significativo y en mayor escala el aglomerado.

\section{Problemática detectada, finalidad y destinatarios} Teniendo en cuenta las contextualizaciones de escalas anteriormente mencionadas, desde el proyecto se detectaron los principales indicadores socioambientales y socioespaciales que caracterizaban los desajustes de la situación encontrada, los que pueden resumirse en:

a) Contaminación de efluentes, bajo mantenimiento, conservación y adecuación socioespacial del área jurisdiccional intermedia del aglomerado urbano, lo que provoca riesgo de salud ambiental en aguas de superficies, napas y suelos, principalmente en torno al arroyo El Rey.

b) Insuficiente ponderación, equipamiento y normatividad en los criterios de sustentabilidad bioambiental, teniendo en cuenta que se trata de un área protegida parte uno de los humedales de reserva nacional, el sitio Ramsar Jaaukanigás. En este sentido, si bien las industrias locales tratan parcialmente los residuos, no cumplen un ciclo satisfactorio aeróbico-anaeróbico.

c) Subvaloración y degradación de la imagen ambiental y de los recursos ecológicos, desaprovechando vivencial y existencialmente el sector rurbano híbrido intermedio como potencial espacio público, capaz de generar apropiaciones paisajísticas y de mejorar las condiciones de salud psicosocial de los ciudadanos.

d) Dispersión de la problemática ambiental en instituciones locales, provinciales y nacionales, basadas en estudios, diagnósticos y propuestas en paralelo, por lo cual no se alcanzan un aceptable nivel de compatibilidad ni acuerdos para la actuación remedial mancomunada.

e) Bajo nivel de concientización en la población civil del aglomerado sobre la pérdida paulatina de calidad de vida de los años recientes, tanto en cuanto a los afectados directamente porque residen en situación próxima al área con consecuencias directas como respecto de los impactos de la población distal. f) Desarticulación de políticas dinámicas urbanas de actividades mixtas para el sostenimiento integracionista de calidad de vida bajo las condiciones particulares físicas, ambientales y espaciales del área de contrastación.

g) Inseguridad y riesgo de accidentes viales en los movimientos y traslados de los flujos vehiculares y peatonales del borde urbano limitador de ambas ciudades, especialmente en las proximidades de la Ruta Nacional $N^{\circ} 11$. 
Con estas consideraciones, el grupo extensionista de docentes investigadores se propuso un objetivo general: la construcción de una proyectualidad multiactoral, participativa, integracionista y democratizada. A partir de una mirada heterológica y de saberes transdisciplinares devenidos de las investigaciones que vienen desarrollando los integrantes del equipo, ${ }^{1}$ se aborda la diversidad problemática de la ciudad contemporánea indagando a la vez la cultura socioambiental local. Esta perspectiva incluye la reciprocidad de saberes producto del diálogo con instituciones representativas de la vida civil, política y educativa, conformando universos referenciales que evidencian la relación de la universidad con el medio.

A ese respecto, en el orden social e institucional, se fomentó la concientización y la participación de las instituciones locales, zonales y regionales para definir una estrategia proyectual y de acción. A partir de la inclusión de contextos socioculturales determinados y determinantes, en el ámbito de la ciudad se promovieron conductas participativas en el ciudadano hacia las problemáticas de interés social comunitario.

En el orden del saneamiento ambiental, el proyecto incluyó la puesta en valor y potenciación del sitio Ramsar la mejora en las condiciones de habitabilidad y confort ambiental de los barrios próximos al arroyo El Rey; el diseño de equipamientos sostenibles para la generación de energía alternativa sustentable, adaptables a situaciones paisajísticas de inestabilidad hidrológica geográfica del aglomerado; la puesta en el ciclo sinérgico de los efluentes contaminantes industriales y la recuperación del valor paisajístico, público y apropiable del área de intervención.

En el orden académico, se fomentó el sentido democratizador del debate universitario, transfiriendo experiencias mediante la modalidad de talleres participativos de opinión y debate público interestamental, logrando transferencia de insumos investigativos al caso concreto en relación con las demandas específicas locales. La participación de estudiantes, jóvenes graduados, cientibecarios y tesistas en el proyecto, potenció su inclusión en las organizaciones intermedias de la sociedad civil e instituciones barriales del medio, con la promoción de competencias universitarias inherentes en cuanto a la vinculación universidad, medio social y sus actores. A su vez, por tratarse de un proyecto integracionista de saneamiento ambiental con impacto regional, se pretendió generar un primer enclave de una franja económica de beneficiarios referida a turismo bioambiental que ampliaría los destinatarios a una escala mayor territorial. Esta hipótesis incluye a la ciudad de Goya, Corrientes, con la cual la ciudad de Reconquista se conecta por servicio fluvial de balsas de cargas, vehículos y pasajeros, atravesando una zona de islas de alto valor paisajístico y biodiversidad del río Paraná.

\section{Instituciones participantes y aportes al proyecto}

El equipo extensionista se conformó transdisciplinarmente con participantes académicos y sociales, fue convocado un espectro consultivo de instituciones del medio que aportaron información de base para el reconocimiento del estado de situación y el desarrollo del proyecto. Las instituciones participantes fueron las siguientes:

- La Escuela Universitaria del Alimento (Centro Universitario Reconquista UNL) aportó sobre la temática de la contaminación del arroyo El Rey por desechos industriales y cloacales e incumbencias de la institución en el monitoreo del arroyo y su influencia en suelos y producción de alimentos. Brindó espacio físico para la realización de talleres y facilitó el contacto con los docentes que llevaban adelante investigaciones sobre tratamiento de efluentes y degradación de vertidos agroindustriales.

- La Federación de Asociaciones Vecinales Reconquista contribuyó con planimetría social de las vecinales por barrio y su estructuración, información sobre el desarrollo social actual, planes, programas y líneas de acción a futuro. Convocó a los talleres de participación y opinión sobre la problemática del proyecto a grupos destinatarios a nivel vecinal y difundió los eventos.

- La Municipalidad de Reconquista comunicó aspectos del Plan Estratégico Reconquista en vigencia, sus avances y acciones desarrolladas a la fecha, información técnica, catastral, infraestructural, medio ambiente y planes urbanos. Colaboró para la realización de convocatorias a talleres de participación y opinión sobre la problemática del proyecto a los grupos destinatarios de la comunidad a nivel del municipio y facilitó la difusión a dichos eventos.

- El Instituto Nacional de Tecnología Alimentaria, Estación Experimental Reconquista, colaboró con información técnica bioambiental de las condiciones actuales del aglomerado e indicadores actuales y proyecciones a futuro sobre desarrollo económico y empleo de la región, material específico sobre suelos, impacto ambiental de la sojización de la región, proyecto de biodigestores en estudio por la institución y especies vegetales autóctonas de importancia ambiental. Aportó profesionalmente para la realización de talleres de participación y opinión en la ciudad de Reconquista sobre la problemática.

- El Colegio de Arquitectos de la Provincia de Santa Fe, Distrito 6 Reconquista, acercó material institucional sobre el problema de la contaminación ambiental y material bibliográfico local y regional de la institución sobre el aglomerado Reconquista/ Avellaneda. Ofreció espacio físico para la realización de reuniones y encuentros con los profesionales del medio con injerencia en la problemática del proyecto.
1) Los integrantes forman parte del Curso de Acción de Investigación+Desarro-
Ilo 2009 (CAl+D) Red de Problemáticas Urbanas Contemporáneas (SeCyT-UNL). 


\section{6}

el proyecto incluyó

la puesta en valor y potenciación

del sitio Ramsar, la mejora en

las condiciones de habitabilidad

y confort ambiental de los barrios

próximos al arroyo El Rey

\section{Metodología y estrategias}

Metodológicamente se desplegó un mapa de cinco articulaciones:

1) Acción participativa: base operativa que canaliza necesidades, aspiraciones, estados de reflexión y conflictos de los habitantes, para la planificación, monitoreo, evaluación y comunicación participativa.

2) Etnometodología interpretativa: el sitio como observatorio conceptual y de las interacciones con la situación urbana, mediante la observación participativa. Comprensión de las interacciones con lo cotidiano.

3) Trabajo de campo desde una óptica socioecológica: pautas y regímenes para el desarrollo de modelos de diagnóstico que permitan la identificación de los factores asociados a la segregación socio espacial, vulnerabilidad socio urbanística y al riesgo social.

4) Analíticas urbanas: relación estructural urbana considerando categorías analíticas para el espacio público urbano en la unidad, fragmentos y dispersiones.

5) Interactuación sintomática de la ciudad: abordaje de la ciudad concreta desde un proyecto social y participativo del territorio, mediante el proyecto extensionista como laboratorio social.

Estratégicamente, la vinculación participativa con el medio se efectuó a través de talleres con las instituciones involucradas y talleres abiertos con difusión pública para la participación de la sociedad civil. Se realizó al inicio del proyecto un taller institucional en el cual se expusieron la problemática a abordar con el trabajo y la visión extensionista del grupo académico, un segundo taller institucional que tomó la problemática de Reconquista y la región, y un taller abierto participativo de debate y opinión donde se presentaron a la ciudadanía el proyecto, el equipo extensionista, los antecedentes, y se recabaron las primeras opiniones a través de actas del encuentro. Sobre el final, se realizó un taller abierto de difusión pública con exposición de los aportes y propuestas proyectuales para el saneamiento ambiental del sector.

\section{Plan de intervenciones socioambiental y socioespacial}

Desde el enfoque de una proyectualidad abierta, se han afrontado los objetivos de restitución ambiental y puesta en valor de los sectores seleccionados para la intervención, se mejoraron las condiciones de habitabilidad y salubridad, se propició una paisajística psicofísica flexible y sustentable con equipamientos sostenibles, y se potenciaron el humedal y el Sitio Ramsar a través de la propuesta proyectual estructurada en tres escalas de intervención:

- Escala macro: relación del aglomerado Reconquista/Avellaneda con su designación de Sitio Ramsar, inclusión del área portuaria de Reconquista con el ecosistema del río Paraná y con el puerto de Goya, Corrientes. 


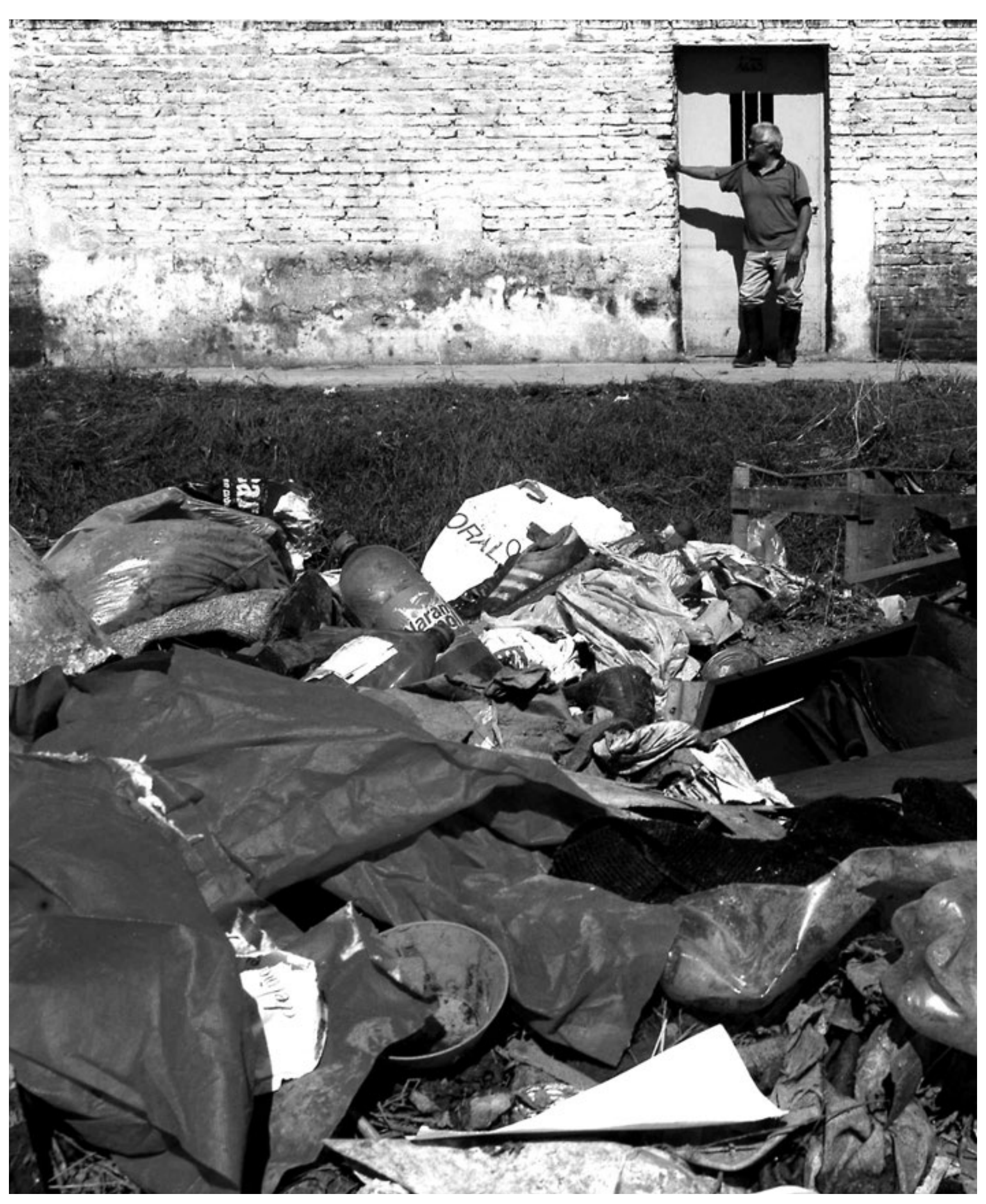


Estado al momento de la propuesta: se detectó información ambiental dispersa y falta de un ámbito de contralor ecoambiental y educativo que instalara la problemática de valoración, conservación y remediación de los recursos ambientales existentes y los afectados. Decisión proyectual: proponer una Estación Biológica experimental y un Centro de Visitantes. Resolver la complementariedad de actividades urbanas, integrar al puerto usos de navegación de carga y pasajeros con áreas de ocio y paseos urbanos, en tanto la Estación Biológica es una presencia institucional pública a través de la ciencia y la educación.

La Estación se plantea como una edilicia flexible articuladora de áreas educativas con la finalidad de instalar el problema ambiental sistemáticamente en currículos escolares, áreas científicas de observación, seguimiento y contralor bioambiental y como centro de visitantes para la comprensión del valor del humedal para los visitantes turísticos y vecinos de las ciudades. Se estructuraría con sectores de botánico acuático, laboratorios de investigación, plataformas de observación, recorridos públicos de apropiación, aulas y salón de usos múltiples, albergue para científicos y visitantes, área comercial de productos zonales y difusión de conocimientos sobre la problemática en soportes impresos y digitales.

Se sugirió una política de participación mixta pública y privada: el suelo para radicar el emprendimiento aportado por el municipio y gestión mixta —municipio emprendedores privados- para el desarrollo y administración del conjunto edilicio.

En el área científica y educativa pública, se presentó una propuesta para llevar adelante convenios de formación de recursos humanos y desarrollo científico con miras a industrias más limpias ambientalmente. En las áreas de albergue y comercial, la idea es que la inversión y administración sean privadas, con contralor de gestión pública.

- Escala media: borde urbano Reconquista/Avellaneda sobre el arroyo El Rey, área de localización de industrias, Camping Municipal Reconquista y relación con los barrios próximos al sector.

Estado al momento de la propuesta: se detectó como el área más afectada ambientalmente al arroyo El Rey, contaminado en sus aguas y bordes costeros. Las industrias no completan el ciclo de saneamiento de sus efluentes y el camping y los barrios sufren la contaminación y olores nauseabundos en aguas y suelo.

Decisión proyectual: rescate de las áreas afectadas como espacios públicos paisajísticos, remediación de la contaminación por efluentes industriales a través de biodigestores para las principales industrias y potenciación del vivero existente.

El área de espacio público se plantea como un paseo de senderos que sigue la margen del arroyo y en el cual se localizan tres miradores estratégicos para la observación urbano-paisajística de todo el aglomerado. Los senderos y los miradores se materializan en estructuras y cerramientos de maderas de la región y cerramientos verdes utilizando especies autóctonas. Se tomó como antecedente el desarrollo de una tesis de grado llevada adelante en el marco de un proyecto de investigación de uno de los integrantes del equipo extensionista.

El planteamiento para el área de biodigestores fue considerarla no sólo como un área técnica de descontaminación sino como un espacio de accesibilidad pública para el conocimiento educativo de instalaciones y de producción de energía alternativa, integrada a los espacios públicos del sector. Los biodigestores diseñados aprovechan la digestión anaeróbica de residuos biodegradables en un proceso natural que descompone biomasa en un entorno húmedo y anóxico a través de la actividad bacteriológica. No requieren el suministro de ningún reactivo o químico y pueden, además, producir biogás, utilizar sus cargas sólidas como fertilizantes naturales para la mejora y recuperación de los suelos afectados y transformar el biogás en energía eléctrica y alimentar generadores para las industrias. En el proyecto, las cargas solidas útiles de los biodigestores se transforman en fertilizantes de insumo para el vivero municipal, con un excedente comercializable en el mercado local.

También en esta escala se propuso una política de participación mixta pública y privada: los biodigestores construidos por las industrias fueron dimensionados de modo que, además de proveer de biogás a las mismas, tengan un remanente capaz de ser aprovechado en el aglomerado, administrado por un organismo público de energía.

El paseo y el vivero fueron pensados como gestión e inversión pública municipal, destacándose el mantenimiento participativo a través de un programa de inclusión de escolares locales, en un plan propuesto de acción y enseñanza educativa formal. Las intervenciones en el sitio se completan con área pública para observación valorativa y de experiencia ambiental, venta de la producción del vivero y paseo libre en conexión con las márgenes del arroyo El Rey.

- Escala micro: área del Camping Municipal Reconquista sobre el arroyo El Rey y sector del centro cívico del nodo Reconquista de la provincia de Santa Fe.

Estado al momento de la propuesta: se observó un buen mantenimiento del camping pero con baja apropiación pública de las instalaciones debido a la contaminación ambiental.

Decisión proyectual: favorecer el mejoramiento del espacio público complementando las actividades propias del camping con demandas de usos urbanos e integrando el proyecto del centro cívico con un trabajo morfológico en sus espacios exteriores. La estrategia de intervención plantea un área de arribo al camping y equipamiento sencillo, práctico, sustentable y sostenible. Una edilicia con características de mirador, como equipamiento necesario para el centro cívico de Reconquista, articulada con planta baja libre para actividades varias de franca accesibilidad pública, primer piso con pileta cubierta climatizada para uso del camping e instituciones de la ciudad, dos pisos de estacionamiento para los usuarios acampantes, y el último piso con salón de usos 
múltiples, cantina, balcones miradores y sanitarios, equipamiento para el ocio de los ciudadanos. La intervención se propone como oportunidad viable de dotar de instalaciones de escala urbana a la ciudad, focalizadas en un sector público significativo, como lo es el camping municipal.

Respecto del paisaje, caracterizado por la organicidad de especies nativas, se propone una metaforización paisajística mediante el diseño de un área boscosa, un plan sistemático de forestación, y ritmando la naturaleza.

Desde la perspectiva de la política de gestión e inversión del sitio, se sugirió que la arquitectura a incorporar se enmarque en un plan de inversiones pública y privada, y se propuso que las áreas de piletas y estacionamiento sean gestionadas y administradas por la Municipalidad en coordinación con el sector de salón multipropósitos y gastronomía con mayor injerencia privada.

\section{Conclusiones}

El trabajo de extensión interpeló la confrontación entre políticas públicas e intereses sectoriales privados, poniendo énfasis en las políticas públicas de gestión mixta.

Así, el problema ambiental, su equilibrio económico, su factibilidad de inversión, las ganancias socioespaciales, la recuperación y mejora de salubridad poblacional, la restitución del valor del espacio público, pueden ser analizados, debatidos y remediados como un problema de todos -instituciones y población civil. La clave del trabajo consistió en generar políticas públicas que fomenten participación y educación activa multiactoral.

Desde esta perspectiva, la integración en el grupo extensionista respecto de conocimientos de fuentes académicas, profesionales y empíricas locales, sumada a la coordinación del trabajo mancomunado entre instituciones, posibilitó desarrollar una experiencia inédita para todos los actores involucrados, la que se espera tenga una continuidad, cuestión que ya fue vislumbrada al momento de la presentación pública de la propuesta final. En tal sentido, se destaca la muy buena recepción y el apoyo a la propuesta y a las actividades desarrolladas por parte de los funcionarios involucrados, ${ }^{2}$ quienes, además de ser los convocantes permanentes de talleres y encuentros, apoyaron la estrategia de mancomunar plenariamente decisiones que afectan la vida civil. Por otra parte, para todo el grupo extensionista académico, se vio plasmada una línea de acción en el territorio donde la tríada docencia, investigación y extensión produjo un espacio de concurrencia capaz de atender situaciones concretas vinculando universidad, medio social y organizaciones intermedias de la sociedad civil.

\section{Bibliografía}

Harvey, D. (2009). Espaços de Esperança. São Pablo: Editorial Loyola.

Municipalidad de Reconquista (2010). "Plan Estratégico Reconquista". Documentos institucionales.

Panigatti, J. L. (2010). Argentina 200 años, 200 suelos. Buenos Aires: Editorial

INTA.

Santos, R. F. (2004). Planejamento Ambiental: Teoria e Prática. São Paulo: Oficina

de Textos.

Sassen, S. (2007). Una Sociología de la Globalización. Buenos Aires: Katz.

Tena, R. (2005). "El urbanismo sociocultural en América Latina. Ciudad de México

y São Pablo". Tesis doctoral no publicada. México DF.

Venturi Ferriolo, M. (2009). Percepire paesaggi. La potenza dello sguardo. Torino:

Bollati Boringhieri.

Vitale, M. A. (2012). "Transdisciplina - Ciudad Hoy". En Bassani, J. (ed.). PDP

Mapografías. Facultad de Arquitectura, Universidad de San Pablo.

Vitale, M. A. (2013). "Paisaje heterológico de las nuevas formas indiciales". En

Pesce, G. y Assen, L. (ed.). Arquitetura da Cidade na América Contemporânea.

Raízes, ritmos e desígnios. Florianópolis: Editora da UFSC.

2) Especialmente de Promoción Social y Desarrollo Comunitario de la Municipalidad y del Plan Estratégico de la ciudad. 